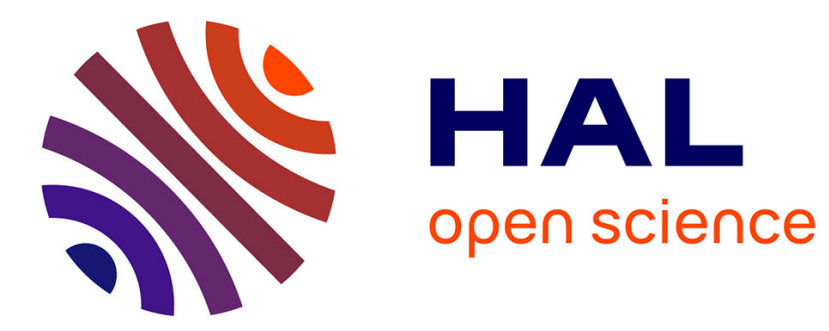

\title{
Solid state chemistry of ionic fluorides
}

Josik Portier

\section{- To cite this version:}

Josik Portier. Solid state chemistry of ionic fluorides. Angewandte Chemie International Edition, 1976, 15 (8), pp.475-486. 10.1002/anie.197604751 . hal-00131557

\section{HAL Id: hal-00131557 https://hal.science/hal-00131557}

Submitted on 13 Dec 2021

HAL is a multi-disciplinary open access archive for the deposit and dissemination of scientific research documents, whether they are published or not. The documents may come from teaching and research institutions in France or abroad, or from public or private research centers.
L'archive ouverte pluridisciplinaire HAL, est destinée au dépôt et à la diffusion de documents scientifiques de niveau recherche, publiés ou non, émanant des établissements d'enseignement et de recherche français ou étrangers, des laboratoires publics ou privés. 


\title{
Solid State Chemistry of Ionic Fluorides
}

\author{
By Josik Portier $\left.{ }^{[*}\right]$
}

The results of intensive pure research into the chemistry and physics of fluorides can be pieced together to give an overall picture whose discernible outlines hold promise of numerous new compounds having unusual and in some cases unique properties. Modern technology is called upon to exploit them.

\section{Introduction}

The properties of some fluorinated inorganic materials have been known since antiquity. However, systematic research in this area began less than one hundred years ago, after Moissan had succeeded in isolating elemental fluorine. Until 1940 , research in the field of fluorine chemistry was limited due to technical difficulties. During the course of World War II, fluorine chemistry began to develop rapidly: the isotopic separation of uranium utilizing uranium hexafluoride required large quantites of fluorine. The handling of the gas was rapidly simplified because of the appearance of corrosion resistant materials, and by the industrial production of liquified hydrogen fluoride and compressed fluorine.

This spectacular development rapidly led to numerous applications, especially of fluorochlorohydrocarbons (freons), tetrafluoroethylene polymers (teflon), sulfur hexafluoride (for its dielectric properties), etc. The applications of solid inorganic fluorides are much more limited. One can mention $\mathrm{AlF}_{3}$ in aluminum metallurgy and the use of various inorganic fluorides in organic fluorination.

A survey shows, however, that in the specialized journals of solid state physical chemistry, ten per cent of the publications are dedicated to fluorides. This interest of researchers for

[*] Dr. J. Portier

Laboratoire de Chimie du Solide du C.N.R.S

Université de Bordeaux I

351, cours de la Liberation

F-33405 Talence (France) fluorine compounds far exceeds its present industrial application, suggesting that the potential applications of inorganic fluorides are numerous and varied. It is this aspect that we shall develop in this contribution.

2. The Fundamental Properties of the $\mathbf{F}^{-}$IonConsequences for the Physicochemical Properties of Fluorides

Inorganic fluorides have specific properties which distinguish them from other compounds. Since these properties are due to the characteristics of the fluoride ion, it would therefore be logical to start by considering this ion and comparing its properties with those of its neighbors in the Periodic Classification, $\mathrm{O}^{2-}, \mathrm{S}^{2-}, \mathrm{Cl}^{-[1]}$.

Fluorine possesses the electron configuration $1 \mathrm{~s}^{2} 2 \mathrm{~s}^{2} 2 \mathrm{p}^{5}$. In the $\mathrm{F}_{2}$ molecule each fluorine atom contributes an electron to a single covalent bond. The intramolecular distance is $1.435 \AA$. The dissociation energy of the molecule $(37.8 \mathrm{kcal} / \mathrm{mol}$ at $298.15 \mathrm{~K})$ is extremely low $\left(\mathrm{O}_{2}, 118.32 ; \mathrm{Cl}_{2}, 58.02 ; \mathrm{S}_{2}\right.$, $102 \mathrm{kcal} / \mathrm{mol}$ ). Fluorine is the most electronegative element (F, 4.0; O 3.5; Cl, 3.0; S 2.5 on Pauling's scale) and it will easily adopt the electronic structure of its noble gas neighbor neon $\left(1 \mathrm{~s}^{2} 2 \mathrm{~s}^{2} 2 \mathrm{p}^{6}\right)$, leading to the $\mathrm{F}^{-}$ion which is practically the only stable ionic form of fluorine.

These two properties, low'dissociation energy of the molecule and very high electronegativity, explain the history of fluorine chemistry. Its late discovery by Moissan and the failure of earlier attempted preparations by Davy, Ampère, 
and Faraday are due to the fact that fluorine reacts with its environment immediately upon formation. It is now known that fluorine reacts with almost all the elements including noble gases-except helium, neon, and argon. Its handling is only possible because of the passivation of certain metals by a protective layer of a nonvolatile fluoride (nickel for example) or the chemical inertness of fluorinated polymers.

This extraordinary reactivity and the exothermic character of the reactions in which it is involved have interested researchers in the fields of rocket propulsion ${ }^{[2]}$. Indeed, on reaction with hydrogen it gives far higher combustion temperatures $\left(4700^{\circ} \mathrm{C}\right)$ than those obtained with oxygen $\left(3250^{\circ} \mathrm{C}\right)$. As a result, the specific impulse obtained is $380 \mathrm{~s}$ whereas it is less than $365 \mathrm{~s}$ with oxygen. The technical development of propellants which function with the $\mathrm{F}_{2}-\mathrm{H}_{2}$ couple has been hampered because of the high chemical reactivity of the halogen as well as the toxic nature of the combustion products. It seems, however, that some tests have been undertaken in the USSR and USA (NASA) with oxygen enriched with fluorine.

The extreme electronegativity of fluorine largely explains the properties of fluorides, which are due mainly to the localized character of the electron: covalence is weak and there are no known fluorides having metallic character.

The ionic radius of the fluoride is of the order $1.33 \AA$ according to Ahrens. It is practically the smallest anion. Only the hydride ion in certain combinations has a smaller ionic radius $(\approx 1.20 \AA)$. As a result, the $\mathrm{F}^{-}$ion is highly mobile in crystal lattices. This property will be discussed later on.

Strong electronegativity and short cation-anion distances confer a high lattice energy upon the fluorides. Their melting and boiling points are therefore higher than those of the other halides. However, these temperatures are still nearly always lower for the fluorides than for the oxides, because the single negative charge of the $\mathrm{F}^{-}$ion limits their coulombic energy.

\section{Chemical and Crystallographic Properties of Fluo- rides}

As a general rule, inorganic fluorides are very inert towards other elements; no halogen or chalcogen is able to displace $\mathrm{F}$ from its compounds. Instead, fluorination of oxides is always strongly exothermic:

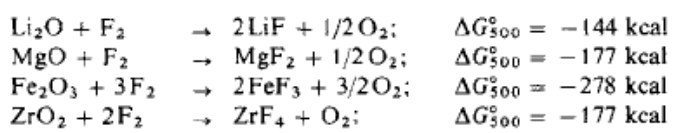

A different situation arises when one comes to the hydrogenated compounds. Water and ammonia generally react with the fluorides giving rise in a first step to hydrogen fluoride having a very high bond energy $(135 \mathrm{kcal} / \mathrm{mol})$. For example, in the case of rare earth fluorides, the following reactions are observed ${ }^{[3,4]}$ :

$\mathrm{LaF}_{3}+\mathrm{H}_{2} \mathrm{O} \rightarrow \mathrm{LaOF}+2 \mathrm{HF}$

$2 \mathrm{LaF}_{3}+4 \mathrm{NH}_{3} \rightarrow \mathrm{La}_{2} \mathrm{NF}_{3}+3 \mathrm{NH}_{4} \mathrm{~F}$

The final products are the oxides or nitrides.
The hydrolysis reaction constitutes a restraint to the practical application of fluoride. In fact, living in an environment in which the active principles are water and oxygen, the engineer tends to utilize the oxides whose preparation and handling are simpler than those of the fluorides.

$\mathrm{F}^{-}$has an ionic radius close to that of $\mathrm{O}^{2-}$. As a result, it is possible to replace oxygen by fluorine in a large number of oxides (Table 1). Owing to the differences in the ionic charges, this substitution leads to a change in the oxidation state of the cations. However, this substitution does not succeed in all cases. For instance, it does not seem possible to prepare solid solutions of sodium chloride type. Lithium fluoride does not react with magnesium oxide, although the respective radii of the anions and cations are very similar. In certain structures an ordered distribution of oxygen and fluorine occurs. This is the case, for example, in certain rare earth oxide fluorides. They have a cubic symmetry corresponding to anionic disorder at high temperatures, but display a trigonal symmetry at low temperatures corresponding to an order between oxygen and fluorine ${ }^{[3]}$.

Table 1. Substitution of $\mathrm{O}^{2-}$ by $\mathrm{F}^{-}$in oxide lattices.

\begin{tabular}{llll}
\hline Structure & Formula & Example & Mechanism \\
\hline rutile & $\mathrm{AO}_{2-x} \mathrm{~F}_{x}$ & $\mathrm{VO}_{2-x} \mathrm{~F}_{x}$ & $\mathrm{O}^{2-}+\mathrm{V}^{4+}=\mathrm{F}^{-}+\mathrm{V}^{3+}[5]$ \\
spinel & $\mathrm{AB}_{2} \mathrm{O}_{4-x} \mathrm{~F}_{x}$ & $\mathrm{Fe}_{3} \mathrm{O}_{4-x} \mathrm{~F}_{x}$ & $\mathrm{O}^{2-}+\mathrm{Fe}^{3+}=\mathrm{F}^{-}+\mathrm{Fe}^{2+}[6]$ \\
garnet & $\mathrm{A}_{3} \mathrm{~B}_{3} \mathrm{C}_{2} \mathrm{O}_{12-x} \mathrm{~F}_{x}$ & $\mathrm{Gd}_{3} \mathrm{Fe}_{5} \mathrm{O}_{12-x} \mathrm{~F}_{x} \mathrm{O}^{2-}+\mathrm{Fe}^{3+}=\mathrm{F}^{-}+\mathrm{Fe}^{2+}[7]$ \\
fluorite & $\mathrm{AO}_{1-x} \mathrm{~F}_{1+2 x}$ & $\mathrm{EuO}_{1-x} \mathrm{~F}_{1+2 x}$ & $\mathrm{O}^{2-}=2 \mathrm{~F}^{-}[3]$ \\
\hline
\end{tabular}

Like $\mathrm{O}^{2-}, \mathrm{OH}^{-}$has a similar ionic radius to $\mathrm{F}^{-}$. There exist, for example, very extensive solid solutions between the fluorides and hydroxides of trivalent rare earths, corresponding to the formula $\mathrm{La}\left(\mathrm{OH}_{1-x} \mathrm{~F}_{x}\right)_{3}{ }^{[8]}$.

The solubility of the oxide and hydroxide ions in the fluorides doubtless constitutes an important obstacle to research into fluorides. Such contamination, even in trace quantities, can drastically change the properties of fluorides and it should be carefully controlled.

In a given structure, the fluoride ion can co-exist with many other anions, e.g. those of other halogens $(\mathrm{EuFCl})^{[9]}$, chalcogens $(\mathrm{LaSF})^{[10]}$, and pnictides (ThNF) ${ }^{[11]}$. Although not a general rule, the tendency towards order between the two anions is here more pronounced than with oxygen. This is a consequence of the significant difference in ionic radii and also the difference in charge for the chalcogens and pnictides.

The similarity of the ionic radii of oxygen and fluorine (1.40 and $1.33 \AA$ on Ahrens' scale) suggests a certain analogy

Table 2. Crystallochemical analogies between fuorides and oxides.

\begin{tabular}{llll}
\hline Formula & $\begin{array}{l}\text { Coordination } \\
\text { number } \\
\text { of cation }\end{array}$ & Structure & Example \\
\hline $\mathrm{AX}$ & 6 & $\mathrm{NaCl}$ & $\mathrm{LiF}$ and $\mathrm{MgO}$ \\
$\mathrm{AX}$ & 6 & rutile & $\mathrm{MgF}_{2}$ and $\mathrm{TiO}_{2}$ \\
& 8 & fluorite & $\mathrm{CaF}_{2}$ and $\mathrm{ZrO}_{2}$ \\
$\mathrm{AX}_{3}$ & 6 & $\mathrm{ReO}_{3}$ & $\mathrm{VF}_{3}$ and $\mathrm{ReO}_{3}$ \\
$\mathrm{ABX}_{3}$ & 12,6 & perovskite & $\mathrm{KMgF}_{3}$ and $\mathrm{BaTiO}_{3}$ \\
$\mathrm{AB}_{2} \mathrm{X}_{4}$ & 4,6 & spinel & $\mathrm{Li}_{2} \mathrm{NiF}_{4}$ and $\mathrm{NiFe}_{2} \mathrm{O}_{4}$ \\
$\mathrm{AB}_{2} \mathrm{X}_{6}$ & 6 & trirutile & $\mathrm{LiFe}_{2} \mathrm{~F}_{6}$ and $\mathrm{Fe}_{2} \mathrm{TeO}_{6}$ \\
$\mathrm{~A}_{3} \mathrm{~B}_{3} \mathrm{C}_{2} \mathrm{X}_{12}$ & $4,6,8$ & garnet & $\mathrm{Na}_{3} \mathrm{Li}_{3} \mathrm{Fe}_{2} \mathrm{~F}_{12}$ and \\
& & & $\mathrm{Y}_{3} \mathrm{Fe}_{3} \mathrm{Fe}_{2} \mathrm{O}_{12}$ \\
& & &
\end{tabular}


between oxide and fluorine crystal chemistry. In fact, the same type of coordination and structure is found when the cations have close ionic radii (Table 2).

However, it seems that only a limited structural variety is open to fluorides. This is probably due to the more pronounced ionic character of the bond. Since the structure adopted depends almost solely on stereochemical factors, the influence of the crystal field or covalence being negligible, it can generally be predicted with relative ease. As an example one can cite the compounds of the $3 \mathrm{~d}$ transition elements and of the monovalent elements with the general formula $A_{x} M_{y} F_{z}$ where all structures obey the following basic rules (Fig. 1):

- the transition element is always octahedrally coordinated by fluorine;

- the octahedra $\left(\mathrm{MF}_{6}\right)$ are either isolated or bonded via corners (this rule is true when the radius $A$ of the cation lies between 1 and $1.5 \AA$ );

- all the fluorine atoms participate in the formation of the octahedra $^{[12,13]}$.

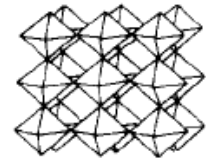

$\left(\mathrm{MF}_{3}\right)$

$\Delta M F_{3}, A_{x} M F_{3}$
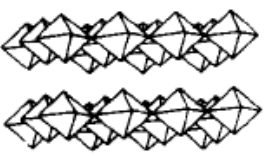

$\left(M F_{4}\right)$

$\triangle M F_{4}, A_{2} M F_{4}$

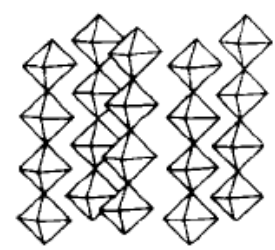

$\left(\mathrm{MF}_{5}\right)$

A127.1 $A_{2} M_{5}$

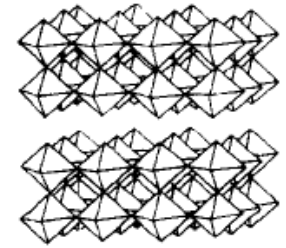

$\left(\mathrm{M}_{2} \mathrm{~F}_{7}\right)$

$A_{3} M_{2} F_{7}$

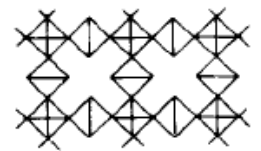

$\left(\mathrm{M}_{3} \mathrm{~F}_{14}\right)$

$\Delta_{5} M_{3} F_{14}$

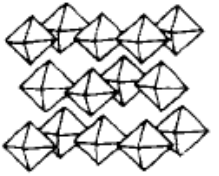

$$
\begin{gathered}
M F_{6} \\
A_{3} M F_{6}
\end{gathered}
$$

Fig. 1. Ideal arrangement of octahedra in transition metal fluorides $A_{x} M_{y} F_{z}$.

From the point of view of the crystal field theory, the ionic character of the fluorine-transition metal bond makes a weak field ligand of halogen. For the d elements this corresponds to a very weak splitting of the crystal field $\Delta_{\text {CF. }}$. This splitting is generally too weak to overcome the mutual repulsion of the d electrons, particularly for the first members of the $3 \mathrm{~d}$ elements as well as for the end members with an oxidation state lower than three. These transition ions then adopt a high spin configuration (Fig. 2). With increasing covalence the crystal field splitting $\Delta_{C F}$ becomes greater, so that ligand field stabilization eventually permits electron pairing and low spin configurations may then be observed for the end members of the $3 \mathrm{~d}$ series, and for $4 \mathrm{~d}$ and $5 \mathrm{~d}$ elements. The transition from one configuration to another is observed for nickel in oxidation state +3 (Table 3 ): the compounds of the $\mathrm{A}_{3} \mathrm{NiF}_{6}$ type $(\mathrm{A}=$ alkali metal) have a low spin configuration at low temperatures and high spin configuration above $100 \mathrm{~K}^{[14,15]}$. However, in the oxides this transition already occurs for cobalt in the oxidation state +3 . Since oxygen gives more covalent bonds than fluorine the crystal field splitting will be greater ${ }^{[16]}$

Table 3. Number and configuration (high spin $\uparrow \uparrow$ or low spin $\uparrow \downarrow \downarrow$ of the $\mathrm{d}$ electrons of stable fiuorides of the first transition series.

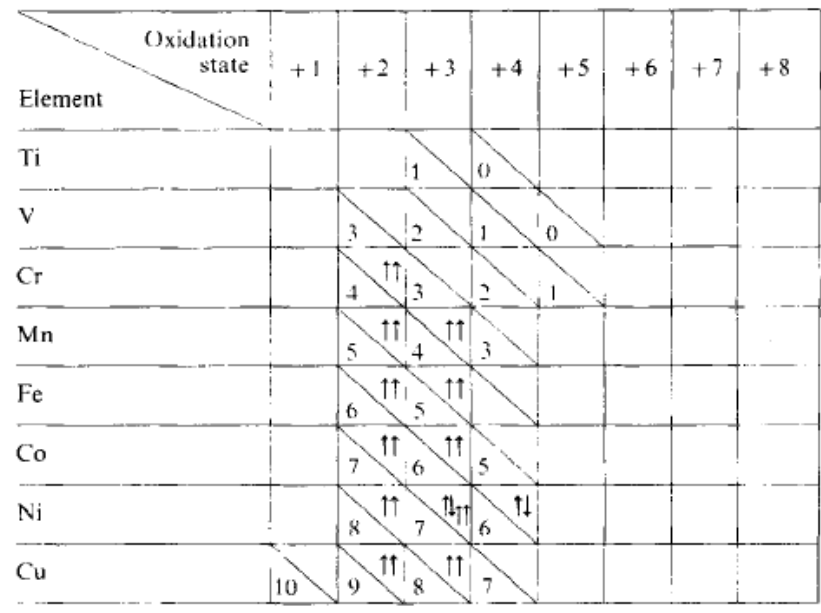

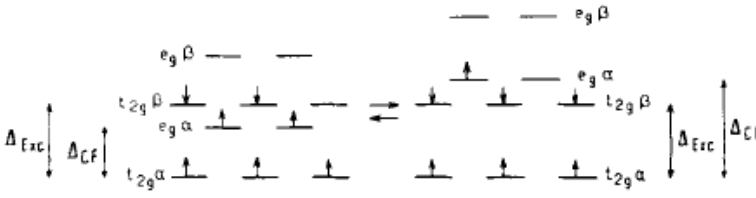

$$
\begin{aligned}
& \text { ¿4127.2 } \quad \mathrm{Ni}^{3+} \quad \mathrm{Ni}^{\text {II }}
\end{aligned}
$$

Fig. 2. High spin $\leftrightarrows$ low spin transition for $\mathrm{Ni}^{3+}$ compounds.

Fluorine is characteristically able to stabilize high oxidation states (Table 4). This particularly interesting aspect of fluorine chemistry has been studied by the German school under the guidance of Klemm and Hoppe ${ }^{[17]}$. This property arises from the pronounced electronegativity of fluorine. It is known that anions of lowest electronegativity stabilize the lowest oxidation states of cations, and the most electronegative anions, the highest oxidation states: iron reacts with iodine to give $\mathrm{FeI}_{2}$, but with fluorine to give $\mathrm{FeF}_{3}$. Since fluorine is the most electronegative element, one should expect to find the highest oxidation states in the fluorides. This hypothesis is sometimes true. For example, copper, silver, and gold do not appear to have an oxidation state higher than +3 in their oxides whereas copper and silver fluorides in the +4 oxidation state are known, and the +5 state has been reported for gold fluorides ${ }^{[18]}$. However, the opposite is often found to apply, as for iron, manganese, ruthenium, rhenium, and osmium. It is difficult to explain this paradox : two contradictory factors may be thought of as governing this phenomenon: 
- the exceptional reactivity and electronegativity of fluorine favor the formation of high oxidation states;

- the ionic character of the metal-fluorine bond imposes a localization of the electrons around the fluorine and therefore a high formal cation charge. For a given oxidation state, this charge is weaker in the oxides where greater electronic delocalization appears owing to the formation either of covalent bonds or bonds having a metallic character. This delocalization diminishes the intercationic repulsions which become large for high oxidation states and therefore tends to increase the lattice energy.

Table 4. Maximum oxidation state of transition metals in oxides and fluorides,

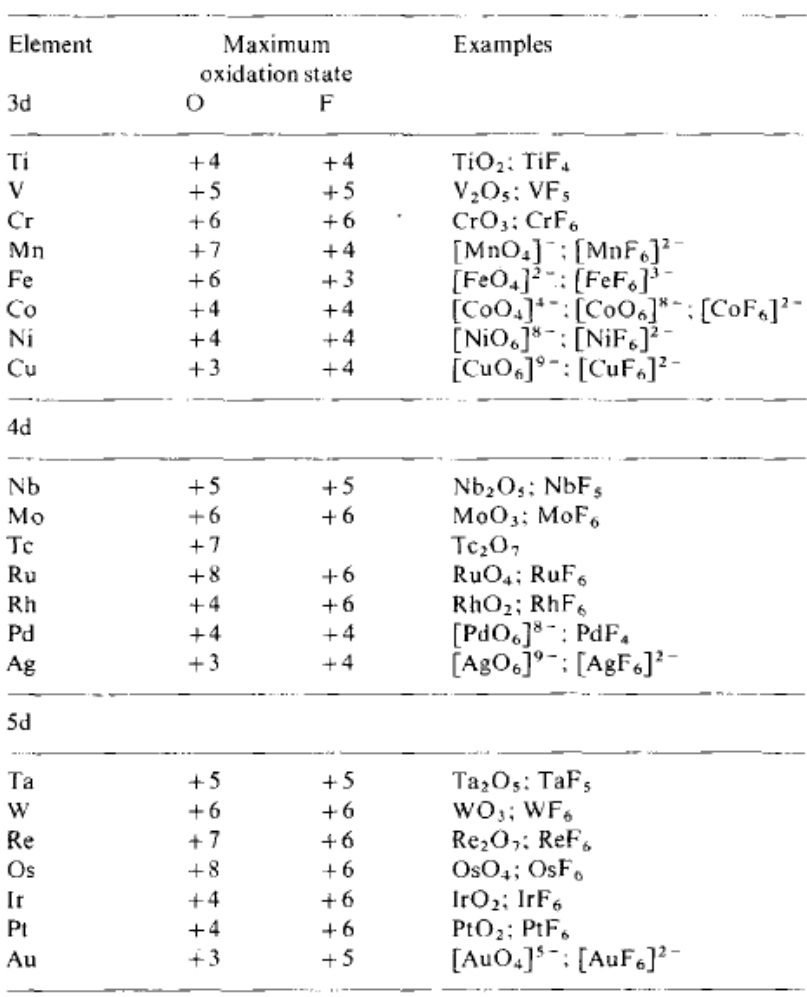

It is interesting to compare the behavior of the fluorides and oxides as to nonstoichiometry. From the point of view of crystal chemistry, this behavior is not fundamentally different. There exist nonstoichiometric fluorides analogous to the oxides; to the oxides of uranium with the fluorite structure $\mathrm{UO}_{2+x}$ there correspond the fluorides of europium with the same structure, $\mathrm{EuF}_{2+x}{ }^{[19]}$; the tungsten bronzes, $\mathrm{M}_{x} \mathrm{WO}_{3}$ have their homologous fluorinated isotypes $\mathrm{M}_{x} \mathrm{FeF}_{3}{ }^{[20]}$. However, it is conceivable that this tendency is less marked in the case of fluorides. Almost all the transition element oxides can contain insufficient or excess oxygen; variations in composition of the $3 \mathrm{~d}$ transition oxides are often particularly large $\left(\mathrm{TiO}_{0.69}\right.$ to $\mathrm{TiO}_{1.33}$ ). However, the corresponding binary fluorides generally have a constant composition. For example, in the iron-oxygen system under equilibrium conditions, two solid solutions are observed whose range extends from $\mathrm{Fe}_{0.96} \mathrm{O}$ to $\mathrm{Fe}_{0.84} \mathrm{O}$ and from $\mathrm{Fe}_{3} \mathrm{O}_{4}$ to $\mathrm{Fe}_{2} \mathrm{O}_{3}$ while in the iron-fluorine system only definite compositions are observed, $\mathrm{FeF}_{2}$ and $\mathrm{FeF}_{3}$ (Fig. 3). This fact should not be surprising; it is well known that the tendency to give definite compounds is all the greater when the electronegativity difference between the ions in the crystal is very high ${ }^{[21]}$.

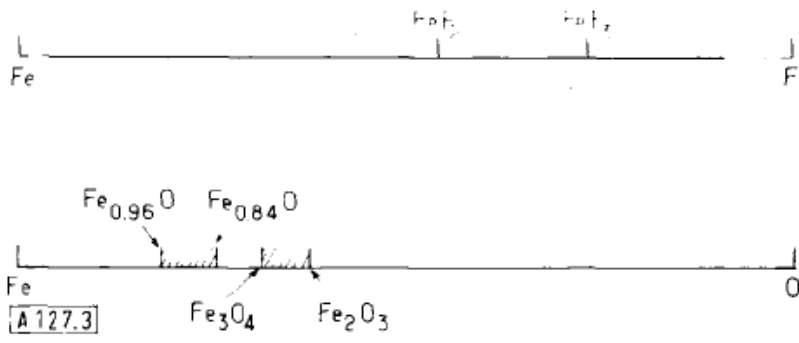

Fig. 3. Comparison between the iron-oxygen and iron-fluorine systems.

Another analogy between the oxides and fluorides is the tendency to form glasses: beryllium fluoride, like silica, combines with alkali fluorides giving glasses whose softening point is very low. The fluorinated glasses do not generally fuse with silicate glasses. This incompatibility, moreover, has been utilized in glassware production: the addition of sodium fluorosilicate to silicate glass brings about opaqueness which is due to the dispersion of the fluorides.

As previously pointed out, the ionic fluorides have moderate melting points associated with a pronounced chemical stability. In the molten state they are almost completely dissociated and have very good solvent properties. These properties suggest a number of applications. In fact, iron age metallurgists added fluorite to iron oxides to lower the melting point of the slag. Moreover, the word "fluor" signifies flow in Latin. It is this property which is used in aluminum metallurgy where bauxite is dissolved in a mixture of fluorite $\left(\mathrm{CaF}_{2}\right)$, cryolite $\left(\mathrm{Na}_{3} \mathrm{AlF}_{6}\right)$, and aluminum fluoride.

This solvent property is also exploited in crystal synthesis. The crystal growth of many oxides can be accomplished from molten fluorides. One can cite the growth of $\mathrm{YIG}\left(\mathrm{Y}_{3} \mathrm{Fe}_{5} \mathrm{O}_{12}\right)$ from melts of $\mathrm{PbO}$ and $\mathrm{PbF}_{2}$.

Another application which appears very promising is the utilization of fluorides in molten salt nuclear reactors ${ }^{[2]}$. This last application offers a number of advantages over the classical solid fuel reactors, particularly in the area of safety. In addition, use of molten fluorides allows continuous elimination of neutron-absorbing fission products. The salts used in these reactors should possess the following properties:

chemical: stability at high temperature and under irradiation, strong dissolving ability for compounds of the fissile elements (U, Pu, Th);

physical: a moderate melting point, low vapor pressure, high thermal conductivity and thermal capacity;

nucleonic: weak neutron absorption and weak moderating action.

Fluorides satisfy all these requirements. Beryllium fluoride is used for its fusibility and lithium fluoride for its fluidity. The fluorides $\mathrm{ThF}_{4}$ and $\mathrm{UF}_{4}$ dissolve in this mixture.

Another related application of molten fluorides is their utilization for thermal energy storage ${ }^{[23}$. Energy consumption is discontinuous while production is continuous. Various methods can be used to meet peak demands: electrochemical (batteries, hydrogen production by electrolysis of water); hydraulic (pumping of water into high reservoirs); mechanical (rapid rotation of flywheels). One elegant solution using fluorides has been proposed. Some eutectic mixtures of alkali or alkaline earth fluorides which have high heat capacities and heats of fusion are heated during the off-hours and subse- 
quently liberate the absorbed heat on demand. This storage capacity per unit volume and weight is theoretically greater than for the conventional systems. In addition, the materials employed are cheap and abundant.

\section{Physical Properties of Fluorides}

In this report, we shall limit our attention to the more characteristic physical properties of saltlike fluorides, and to those having presently implementable or potential practical applications.

\subsection{Electrical Properties}

On the basis of the electronegativity of fluorine, the fluoride can be predicted to be insulators. They have, in fact, no appreciable electric conductivity. The gap between energy bands is usually large $\left(\mathrm{MgF}_{2} \Delta E \approx 12 \mathrm{eV}\right)$. Thus fluorides could be used for making capacitors, were it not for the fact that they are poor dielectrics: their permittivity is not very high in general, but when it is, they show high dielectric losses (Table 5) ${ }^{[24]}$. This last property can be explained by an anionic conductivity. As the smallest anion except for the hydride ion, the fluoride ion is highly mobile and one observes that fluorides have a higher anionic conductivity than oxides. Thus $\mathrm{PbF}_{2}$ which has a similar structure to $\mathrm{ZrO}_{2}$ is a much better conductor than its oxygenated homolog (Fig. 4). This result can, moreover, be generalized. An ionic solid has an ionic conductivity approaching that of the liquid near its melting point. As a consequence, the lower the melting point, the higher the conductivity. $\mathrm{PbF}_{2}$ melts at $855^{\circ} \mathrm{C}, \mathrm{ZrO}_{2}$ at $2700^{\circ} \mathrm{C}$.

These properties of fluorides have already been utilized in ion specific electrodes allowing the determination of fluoride ions in solution. They contain $\mathrm{a} \mathrm{LaF}_{3}$ crystal whose conductivity has been raised by doping with $\mathrm{EuF}_{2}$. On one side of the crystal is placed a normal solution of $\mathrm{F}^{-}$ions, and on the

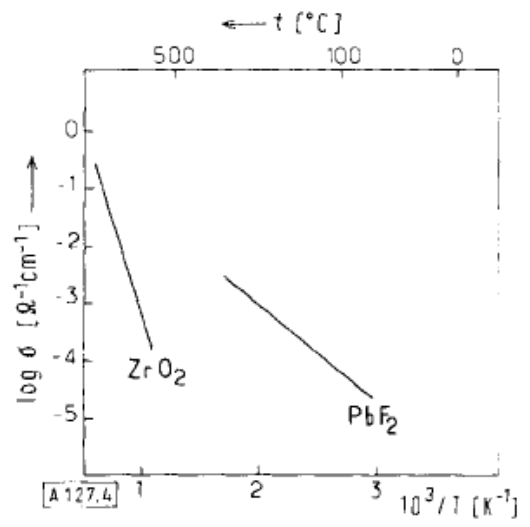

Fig. 4. Change of ionic conductivity with temperature in $\mathrm{ZrO}_{2}$ and $\mathrm{PbF}_{2}$.

other side the solution to be measured. The apparatus works as a concentration cell: a potential difference is established between the two solutions which is proportional to the logarithm of the ratio of their concentrations. A calomel or a silver chloride electrode (Fig. 5) serves as standard.

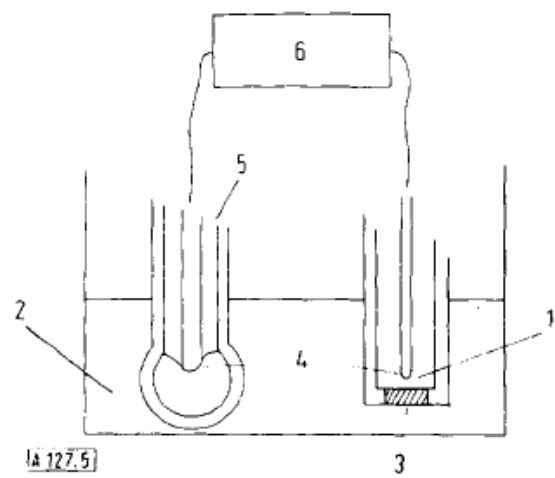

Fig. 5. Ion-specific electrode for fluoride determination (Orion Laboratories). 1, standard solution; 2, sample solution; $3, \mathrm{LaF}_{3}\left(\mathrm{EuF}_{2}\right)$ crystal; $4, \mathrm{Ag} / \mathrm{AgCl}$; 5 , reference electrode (Orion recommends an $\mathrm{Ag} / \mathrm{AgCl}$ electrode with electrolyte bridge and ground glass diaphragm); 6 , potentiometer.

Table 5. Relative dielectric constant $\left(\varepsilon_{r}^{r}\right)$ and loss factor $(\tan \delta)$ of some fluorides.

\begin{tabular}{|c|c|c|c|c|c|c|c|c|}
\hline Structure & $\begin{array}{l}\text { Coordination } \\
\text { number }\end{array}$ & Fluoride & $-50^{\circ} \mathrm{C}$ & $\begin{array}{c}v_{r}^{r} \\
+25^{\circ} \mathrm{C}\end{array}$ & $+150^{\circ} \mathrm{C}$ & $-50^{\circ} \mathrm{C}$ & $\begin{array}{l}\tan \delta \times 10^{4} \\
+25^{\circ} \mathrm{C}\end{array}$ & $+150^{\circ} \mathrm{C}$ \\
\hline $\mathrm{NaCl}[\mathrm{a}]$ & 6 & $\begin{array}{l}\text { LiF } \\
\text { TIF }\end{array}$ & $\begin{array}{l}6 \\
9\end{array}$ & $\begin{array}{l}6 \\
9\end{array}$ & $\begin{array}{c}8 \\
440\end{array}$ & $\begin{array}{r}7 \\
100\end{array}$ & $\begin{array}{r}10 \\
600\end{array}$ & $\begin{array}{r}300 \\
100000\end{array}$ \\
\hline Rutile [a] & 6 & $\begin{array}{l}\mathrm{MgF}_{2} \\
\mathrm{MnF}_{2} \\
\mathrm{ZnF}_{2}\end{array}$ & $\begin{array}{l}10 \\
15 \\
25\end{array}$ & $\begin{array}{l}10 \\
15 \\
30\end{array}$ & $\begin{array}{r}10 \\
20 \\
2000\end{array}$ & $\begin{array}{r}20 \\
30 \\
100\end{array}$ & $\begin{array}{r}20 \\
40 \\
500\end{array}$ & $\begin{array}{r}130 \\
2600 \\
10000\end{array}$ \\
\hline $\mathrm{CaF}_{2}$ & 8 & $\begin{array}{l}\mathrm{CaF}_{2} \\
\mathrm{SrF}_{2} \\
\mathrm{BaF}_{2} \\
\mathrm{CdF}_{2} \\
\mathrm{PbF}_{2-\beta}\end{array}$ & $\begin{array}{l}10 \\
12 \\
10 \\
30 \\
40\end{array}$ & $\begin{array}{l}10 \\
12 \\
10 \\
35 \\
45\end{array}$ & $\begin{array}{r}20 \\
14 \\
10 \\
1000 \\
7000\end{array}$ & $\begin{array}{r}10 \\
20 \\
20 \\
100 \\
100\end{array}$ & $\begin{array}{r}100 \\
50 \\
20 \\
1000 \\
800\end{array}$ & $\begin{array}{r}30000 \\
1000 \\
100 \\
10000 \\
60000\end{array}$ \\
\hline $\begin{array}{l}\text { Distorted } \\
\mathrm{ReO}_{3} \text { type }\end{array}$ & 6 & $\begin{array}{l}\mathrm{AlF}_{3} \\
\mathrm{ScF}_{3} \\
\operatorname{In} \mathrm{F}_{3}\end{array}$ & $\begin{array}{l}6 \\
7 \\
9\end{array}$ & $\begin{array}{l}6 \\
7 \\
9\end{array}$ & $\begin{array}{r}6 \\
9 \\
25\end{array}$ & $\begin{array}{l}80 \\
90 \\
90\end{array}$ & $\begin{array}{l}100 \\
100 \\
200\end{array}$ & $\begin{array}{r}200 \\
500 \\
4000\end{array}$ \\
\hline $\mathrm{YF}_{3}$ & 9 & $\begin{array}{l}\mathrm{YF}_{3} \\
\mathrm{GdF}_{3} \\
\mathrm{BiF}_{3}\end{array}$ & $\begin{array}{r}6 \\
7 \\
50\end{array}$ & $\begin{array}{r}6 \\
7 \\
50\end{array}$ & $\begin{array}{r}7 \\
11 \\
3000\end{array}$ & $\begin{array}{r}30 \\
20 \\
100\end{array}$ & $\begin{array}{r}80 \\
80 \\
800\end{array}$ & $\begin{array}{r}600 \\
3000 \\
60000\end{array}$ \\
\hline Tysonite & 11 & $\mathrm{LaF}_{3}$ & 60 & 60 & 1000 & 200 & 1000 & 120000 \\
\hline $\mathrm{ZrF}_{4}$ & 8 & $\begin{array}{l}\mathrm{ZrF}_{4} \\
\mathrm{ThF}_{4}\end{array}$ & $\begin{array}{l}10 \\
15\end{array}$ & $\begin{array}{l}10 \\
15\end{array}$ & $\begin{array}{l}10 \\
15\end{array}$ & $\begin{array}{l}20 \\
50\end{array}$ & $\begin{array}{r}40 \\
200\end{array}$ & $\begin{array}{r}200 \\
30000\end{array}$ \\
\hline
\end{tabular}

[a] Or related structure. 
The development of electrochemical generators with a solid electrolyte similar to those used in the galvanic chain $S / \beta$ $\mathrm{Al}_{2} \mathrm{O}_{3} / \mathrm{Na}$ can be envisioned. The negative electrode would be composed of a light and reducing metal such as lithium and the positive electrode composed of an easily reducible fluorinated material, such as the fluorides of some transition elements noted in Section 3 (Fig. 6). The change in free energy of such a system is very high and the voltage produced in such a cell should therefore be very high. By applying Nernst's law to the apparatus depicted and by neglecting the reaction of the positive electrode, one obtains a theoretical voltage of more than six volts. However, the practical application of such an apparatus is limited by the relatively weak ionic conducticity of the known materials, which limit the current flow.

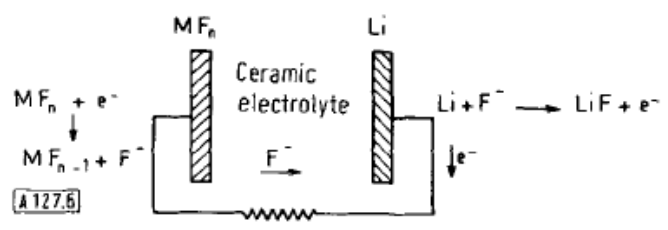

Fig. 6. Electrode reactions in a fluorinated solid electrolyte primary battery.

Other similar devices have been tested; the solid electrolyte was replaced for example, by an aprotic electrolyte $\left(\mathrm{LiClO}_{4}\right.$ in solution of propylene carbonate), the positive electrode is a carbon fluoride $C_{x} F$, and the negative electrode is lithium. The voltage in the open circuit is $3.5 \mathrm{~V}$; the energy densities $3000 \mathrm{Wh} / \mathrm{kg}^{[25]}$.

As an alternative to the solid electrolyte generators and those using a liquid electrolyte, a cell has been proposed which contains a low-melting eutectic mixture of fluorides as electrolyte. The positive electrode is the fluoride of a metal having a high oxidation state and the negative electrode is magnesium. The set-up is heated almost to the melting point of the eutectic. The generator discharges in a few minutes due to the great mobility of $\mathrm{F}^{-}$ions in the molten salts. It was intended to use this apparatus, capable of furnishing a high energy during very short periods, for firing upper stages of space rockets.

Another electrochemical apparatus exploiting the anion conductivity of fluorides deserves mention. A thin layer of $\mathrm{LaF}_{3}$ is placed between a grid-shaped gold cathode and a reactive anode of bismuth (Fig. 7). The characteristics of the cell depend on the atmosphere in which it is placed. When this atmosphere contains reducible gases $\left(\mathrm{O}_{2}, \mathrm{NO}, \mathrm{SO}_{2}\right)$ the current strength rapidly increases for a given applied potential $V_{\mathrm{c}}$. The potential $V_{\mathrm{c}}$ is characteristic of the gaseous species in contact with the cathode while the current is proportional to the concentration of the gas. This device therefore behaves like a selective electrode. This phenomenon is interpreted as a reduction of gas at the cathode, followed by transport of the reduced species in the electrolyte and an oxidation step at the anode. The same cell can function as a fuel cell. Exposed to oxygen it gives in open circuit a voltage of $1.5 \mathrm{~V}$ with a lanthanum anode ${ }^{[26]}$.

As previously mentioned (Section 3), fluorine can replace oxygen in a large number of oxides. This substitution naturally involves some modifications of their electric properties. Gener- ally, one observes an increase in resistivity. The observed phenomenon can, however, be more complex: when fluorine is substituted for oxygen in a transition metal oxide, $\mathrm{M}^{2 n+} \mathrm{O}_{n}^{2-}$,
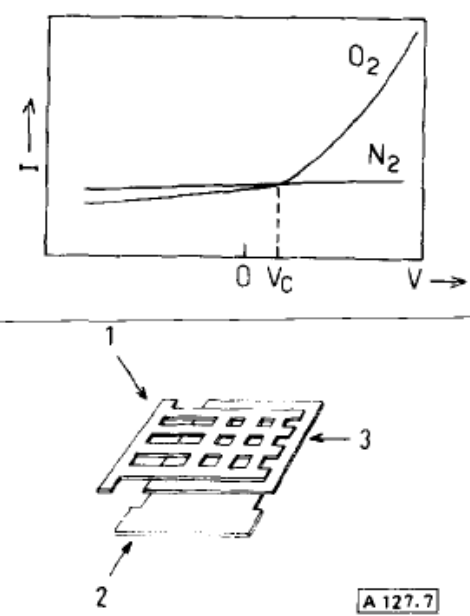

A 127.7

Fig. 7. Gas electrode using solid electrolyte (Philip Morris Research Center, after Laroy et al.). 1, grid cathode; 2 , anode; $3, \mathrm{LaF}_{3}$ electrolyte.

a decrease in the cation charge is necessary to conserve electroneutrality $\left[\mathrm{M}_{(1-x)}^{2 n+} \mathrm{M}_{x}^{(2 x-1)+} \mathrm{O}_{n-x} \mathrm{~F}_{x}\right]$. This corresponds to introduction of an extra d electron into the system. The properties will result from a competition between the localization of electrons by fluorine and increase in the number of these electrons. In $\mathrm{VO}_{2}$, for example, which shows a semiconductor to metal transition there is first of all an observable decrease in the transition temperature which corresponds to a stabilization of the metallic phase and also a gradual progressive disappearance of the metallic character; VOF is again a semiconductor ${ }^{[5]}$.

Studying the Mössbauer effect of compounds containing the same element in two different oxidation states clearly illustrates the localized character of the electrons in the fluoride in comparison with the chalcogenides or pnictides. The oxides or sulfides of this type are generally semiconducting with a low resistivity while the fluorides remain insulators. Figure 8 shows the Mössbauer spectra for $\mathrm{LiFe}^{\mathrm{II}} \mathrm{Fe}^{\mathrm{III}} \mathrm{F}_{6}{ }^{[27]}$ and for $\mathrm{Eu}^{\mathrm{II}} \mathrm{Eu}_{2}^{\mathrm{III}} \mathrm{S}_{4}{ }^{[28]}$. For the first compound, the peaks corresponding to $\mathrm{Fe}^{2+}$ and $\mathrm{Fe}^{3+}$ appear, while for the second, above a certain temperature, only one peak shows up corresponding to a chemical shift intermediate between $\mathrm{Eu}^{2+}$ and $\mathrm{Eu}^{3+}$. If in the fluoride the $\mathrm{d}$ electrons remain localized, in the sulfide a hopping phenomenon appears such that the $\mathrm{Eu}^{2+}$ and $\mathrm{Eu}^{3+}$ ions are no longer distinguishable.

The influence of the substitution of oxygen by fluorine on the properties of the ferroelectric oxides has also been studied. It involves a decrease in the Curie ferroelectric temperature which is easily explained by the ionic character of the metal-fluorine bond. The paraelectric-ferroelectric transition is tied to the alignment of the dipole moments, which involves the distortion of the crystal lattice, and is responsible for the spontaneous polarization $\left(P_{\mathrm{s}}\right)$ when $T<T_{\mathrm{C}}$. This orientation of the dipoles is a function of the interatomic bonds in the material. It is the directional property of the covalent bond which is responsible for the alignment. The introduction of the strongly electronegative fluoride ions weakens the covalence of the bonds and therefore disturbs the alignment of 
the dipoles; the value of $P_{S}$ is then lowered and consequently so is $T_{\mathrm{C}}$. The Curie temperature of $\mathrm{Sr}_{2} \mathrm{KNb}_{5} \mathrm{O}_{15}$ is $420 \mathrm{~K}$ for example, whereas it is only $100 \mathrm{~K}$ for $\mathrm{SrK}_{2} \mathrm{Nb}_{5} \mathrm{O}_{14} \mathrm{~F}^{[29]}$.

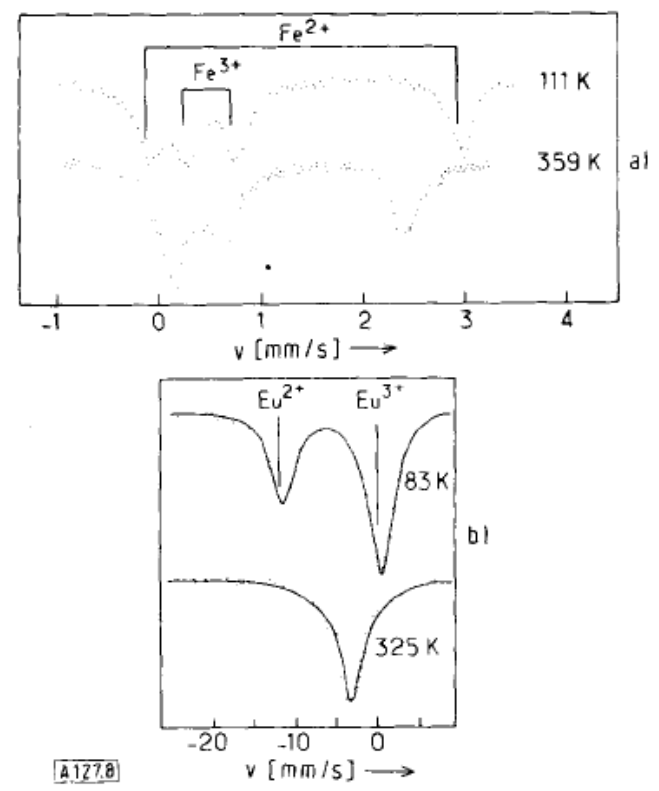

Fig. 8. Electron delocalization illustrated by the Mössbauer effect: a) spectra of $\mathrm{LiFe}_{2} \mathrm{~F}_{6}$ [27]; b) spectra of $\mathrm{Eu}_{3} \mathrm{~S}_{4}$ [28].

In the case of the ceramics this substitution also leads to an increase in dielectric constant and a decrease in dielectric losses. The use of these materials for the production of capacitators has been proposed ${ }^{[30]}$.

\subsection{Magnetic Properties}

Numerous publications are concerned with the magnetic properties of fluorides. This interest of physicists for these materials has several reasons:

- Since fluorides are insulators, their magnetic properties are not influenced by electron delocalization such as often occurs in the oxides or sulfides. The interpretation of the phenomena is therefore simplified.

- Fluorides are transparent in a large spectral range, thus permitting magnetooptical studies.

- A large variety of structures is found in the crystal chemistry of fluorides, in which the transition element is octahedrally coordinated by fluorine. The arrangement of these octahedra makes possible the formation of three-dimensional $\left(\mathrm{AMF}_{3}\right)$, two-dimensional $\left(\mathrm{A}_{2} \mathrm{MF}_{4}\right)$, and one-dimensional structures $\left(\mathrm{A}_{2} \mathrm{MF}_{5}\right)$ each corresponding to a particular magnetic behavior (Fig. 1).

- Fluorine $\left({ }^{19} \mathrm{~F}\right)$ has a nuclear spin $I=1 / 2$ and lends itself, therefore, to NMR experiments which permit determination of the percentage of covalence of the metal-fluorine bonds. In this respect it offers an advantage over oxygen whose commonest isotope ${ }^{16} \mathrm{O}$ has zero nuclear spin.

The magnetic behavior of transition element fluorides is not basically different from that of other insulating solids. Hence diamagnetic, paramagnetic, antiferromagnetic, and ferrimagnetic compounds are all represented.

\subsubsection{Diamagnetic Compounds}

Certain ions of the transition elements whose $d$ layers are partially filled are diamagnetic. This requires an even number of more than $5 \mathrm{~d}$ electrons and a low spin configuration (Table 3). In the $3 \mathrm{~d}$ series, this only applies to tetravalent nickel. By contrast, in the $4 \mathrm{~d}$ and $5 \mathrm{~d}$ series, where the increase of the covalence involves a reinforcement of the crystal field, almost all such ions are diamagnetic (exception $\mathrm{Pd}^{2+}$ ).

\subsubsection{Paramagnetic Compounds}

In the case of transition elements, paramagnetism will be found for those structures whose metal ions are isolated from one another; in other words, when the octahedra do not share any common atom. This is the case for compounds of composition $\mathrm{AMF}_{6}, \mathrm{~A}_{2} \mathrm{MF}_{6}, \mathrm{~A}_{3} \mathrm{MF}_{6}$ (Fig. 1), for which the susceptibility generally follows Curie's law.

Trivalent nickel deviates in its behavior: the low-spin/highspin transition leads to a change in moment of $\mathrm{t} .73 \mu_{\mathrm{B}}$ to $3.7 \mu_{\mathrm{B}}{ }^{[14]}$.

In the case of rare earth metals paramagnetic behavior is generally observed.

\subsubsection{Antiferromagnetic, Ferrimagnetic, and Ferromagnetic Compounds}

When fluorides have structures such that the $\mathrm{MF}_{6}$ octahedra are no longer isolated but share common geometric elements (corners, edges, faces), a magnetic order appears. Antiferromagnetic or ferrimagnetic properties are then observed. In fact, it is known that the energy which couples two spins $S_{i}$ and $S_{j}$ contains an exchange term:

$$
H_{i j}=\sum_{i j} J_{i j} S_{i} S_{j}
$$

The exchange integral $J_{i j}$ is a function of the overlap of the $\mathrm{d}$ orbitals of the $i$-th and $j$-th atoms. For the transition metal fluorides this overlap is direct when the octahedra are linked either by faces or by edges (Fig. $9 \mathrm{a}$ ). When the octahedra are linked by corners, a fluorine atom intervenes between the two paramagnetic atoms. The orbitals of $i$ and $j$ therefore overlap by superexchange involving the $\mathrm{p}$ orbitals of fluorine (Fig. 9b).

The type of interaction depends on the sign of the exchange integral $J(J<0$ antiferromagnetic, $J>0$ ferromagnetic interaction) and the intensity of the interaction, which is directly linked to the ordering temperature, is also dependent on $J$.

For an antiferromagnetic compound the Neel temperature is given by:

$$
T_{\mathrm{N}}=-2 / 3 \frac{J}{k} Z S(S+1)
$$

where $k$ is Boltzmann's constant and $Z$ the number of nearest magnetic neighbors.

The exchange integral $J$ is directly linked to the covalence of the bond. It can be shown that for a coupling using a $\sigma$ bond of the type shown in Figure $9 \mathrm{~b}, J=-2 b^{2} / U$. In this relationship $U$ is the electrostatic repulsion energy brought about by the electron transfer from one ion to another. For the perovskite $\mathrm{KNiF}_{3}$ for example, $U$ is the energy which separates 
the ground state $\mathrm{Ni}^{2+} \mathrm{F}^{-} \mathrm{Ni}^{2+}$ from the excited state $\mathrm{Ni}^{3+} \mathrm{F}^{-}$. $\mathrm{Ni}^{+}$. The transfer integral $b_{\sigma}$ depends on the overlap of the $\mathrm{d}$ and $\mathrm{p}$ orbitals. If $E_{\mathrm{d}}$ and $E_{\mathrm{p}}$ represent respectively the energies of the $\mathrm{d}$ and $\mathrm{p}$ orbitals concerned, $b$ is equal to $f_{\sigma}\left(E_{\mathrm{d}}-E_{\mathrm{p}}\right) ; f_{\sigma}$ being the fraction of the d electron transferred from the $d$ orbital to the $p$ orbital. The transfer coefficient therefore depends on the covalence of the bond. For $\mathrm{KNiF}_{3}$, $f_{\sigma}$ is equal to $3.8 \%$.
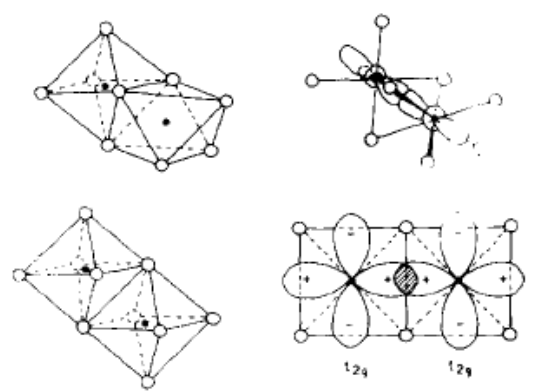

a)
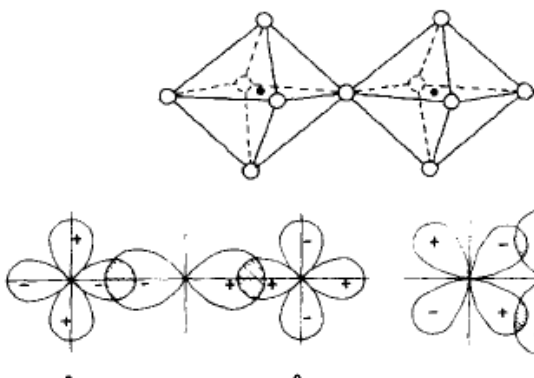

eg

A 127.9

eg

b)

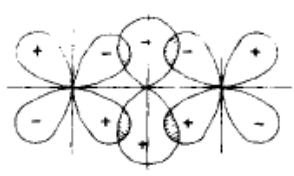

t2g

$t_{2 g}$

Fig. 9. Bonds involved in magnetic interactions (see text)

The sign of $J$ can be predicted from the rules of GoodenoughKanamori. If electron transfer occurs between one half-occupied orbital and another, the interaction is antiferromagnetic. This is the case for $\mathrm{KNiF}_{3}$ which involves overlapping of the orbitals $\mathrm{d}_{\left(x^{2}-y^{2}\right)}-\mathrm{p}-\mathrm{d}_{\left(x^{2}-y^{2}\right)}$ (Fig. $9 \mathrm{~b}$ ), the $\mathrm{d}_{x^{2}-y^{2}}$ orbitals containing only one electron. By contrast, if this same transfer occurs from an occupied or half-occupied orbital to an unoccupied orbital, the interaction will be ferromagnetic as in the example of $\mathrm{Ni}^{2+} \mathrm{Mn}^{4+}\left(\mathrm{F}^{-}\right)_{6}$ (Fig. 9b) in which a transfer is brought about from the half-occupied $\mathrm{e}_{\mathrm{g}}$ orbital of $\mathrm{Ni}^{2+}$ to an empty $\mathrm{e}_{\mathrm{g}}$ orbital of $\mathrm{Mn}^{4+[31]}$.

The preceding considerations allow a comparison between fluorides and oxides. If the same mechanisms are operative, the sign of the interactions will be identical: $\mathrm{LaFeO}_{3}$ and $\mathrm{KMnF}_{3}$ with a perovskite structure are both antiferromagnetic with the same magnetic structure, the $\mathrm{Fe}^{3+}$ and $\mathrm{Mn}^{2+}$ ions being isoelectronic $\left(\mathrm{d}^{5}\right)$. By contrast, the strength of the bonds in a given crystallographic structure will differ: the oxides have a much higher ordering temperature than the fluorides. Although $\mathrm{LaFeO}_{3}$ and $\mathrm{FeF}_{3}$ both have similar antiferromagnetic structures, the oxide has a Néel temperature of $738 \mathrm{~K}$ while that of the fluoride is only $394 \mathrm{~K}$. The exchange integral for a fluoride is therefore only half the size of that in the corresponding oxide.

As a general rule, the ordering temperatures of fluorides are lower than room temperature and practical applications in the field of magnetism are hardly to be expected. Two fluorides, however, are the exceptions to this rule: $\mathrm{FeF}_{3}$ and $\mathrm{CoF}_{3}$. They are antiferromagnetic but have a weak ferromagnetism below their Néel temperatures, which are respectively 394 and $460 \mathrm{~K}$. Owing to its transparency in the visible range, a practical application of the magnetooptical properties of $\mathrm{FeF}_{3}$ was envisioned. In fact, this fluoride could be used as memory material in the treatment of information in the same manner as the lanthanoid orthoferrites. The information is inscribed in these materials by orienting the moments in a small domain of the crystal called a "bubble", which can be displaced by applying a magnetic field. The "bubble" can be usually observed by illuminating the crystal in polarized light because the plane of polarization of the light is rotated in an opposite sense when the light crosses opposing magnetization zones. The ray which crossed the bubble therefore does not have the same polarization as that which crossed the surrounding matter. Unfortunately, the use of $\mathrm{FeF}_{3}$ is hampered by the difficulty in obtaining large crystals. At room temperature $\mathrm{FeF}_{3}$ shows a trigonally distorted $\mathrm{ReO}_{3}$ structure, and becomes cubic at $410^{\circ} \mathrm{C}$. The methods of growing large single crystals generally work above this temperature and therefore the crystallographic transition occurring at $410^{\circ} \mathrm{C}$ during the cooling process produces strong internal tension which destroy the single crystal.

The ferrimagnetic fluorides constitute a particularly interesting class of materials (Table 6$)^{[32]}$. It should be noted that their structures differ from those of ferrimagnetic oxides. In the oxides (spinels, garnets, hexagonal ferrites) the ferrimagnetism arises from the occupation of tetrahedral, octahedral, or dodecahedral sites by the transition elements. The magneti-

Table 6. Characteristic data of ferrimagnetic transition metal Muorides [32]

\begin{tabular}{|c|c|c|c|c|}
\hline Structure & Compound & $T_{\mathrm{C}}[\mathrm{K}]$ & $\Theta_{p}[\mathrm{~K}]$ & $\sigma_{0}[\mu \mathrm{B}]$ \\
\hline \multirow{4}{*}{ Chiolite } & $\mathrm{Na}_{5} \mathrm{~V}_{3} \mathrm{~F}_{14}$ & 21 & 48 & 1.94 \\
\hline & $\mathrm{Na}_{5} \mathrm{Cr}_{3} \mathrm{~F}_{14}$ & 18 & 32 & 2.97 \\
\hline & $\mathrm{Na}_{5} \mathrm{Fe}_{3} \mathrm{~F}_{14}$ & 90 & 95 & 4,98 \\
\hline & $\mathrm{Na}_{5} \mathrm{Co}_{3} \mathrm{~F}_{14}$ & 108 & 110 & 3.10 \\
\hline \multirow[t]{6}{*}{ Hex. $\mathrm{BaTiO}_{3}$} & $\mathrm{RbNiF}_{3}$ & 145 & 300 & 0.76 \\
\hline & $\mathrm{TINiF}_{3}$ & 150 & & \\
\hline & $\mathrm{CsFeF}_{3}$ & 60 & 85 & 1.31 \\
\hline & $\mathrm{NH}_{4} \mathrm{NiF}_{3}$ & 150 & & 0.1 \\
\hline & $\mathrm{CsNiF}_{3}$ & 111 & & 0.53 \\
\hline & $\mathrm{CsCoF}_{3}$ & 50 & 65 & 0.8 \\
\hline \multirow[t]{2}{*}{$\mathrm{C}_{\mathrm{S}_{4}} \mathrm{Mg}_{3} \mathrm{~F}_{10}$} & $\mathrm{Cs}_{4} \mathrm{Ni}_{3} \mathrm{~F}_{10}$ & 15 & 106 & 0.06 \\
\hline & $\mathrm{CS}_{4} \mathrm{Co}_{3} \mathrm{~F}_{10}$ & 33 & 120 & 0.98 \\
\hline \multirow[t]{7}{*}{ Weberite } & $\mathrm{Na}_{2} \mathrm{NiFeF}_{7}$ & 90 & 50 & 1.5 \\
\hline & $\mathrm{Na}_{2} \mathrm{NiCrF}_{7}$ & 4 & & \\
\hline & $\mathrm{Na}_{2} \mathrm{NiCoF}_{7}$ & 126 & & 0.9 \\
\hline & $\mathrm{Na}_{2} \mathrm{Fe}_{2} \mathrm{~F}_{3}$ & 84 & & 0.75 \\
\hline & $\mathrm{Na}_{2} \mathrm{CoFeF}$, & 80 & & 1.2 \\
\hline & $\mathrm{Ag}_{2} \mathrm{NiFeF}$, & 103 & & 2.1 \\
\hline & $\mathrm{Ag}_{2} \mathrm{NiCrF}$ & 10 & & \\
\hline MnAlF $_{5}$ & $\mathrm{MnAl}_{0.45} \mathrm{Fe}_{0.55} \mathrm{~F}_{5}$ & 34 & 136 & \\
\hline \multirow[t]{2}{*}{$\mathrm{Cr}_{2} \mathrm{~F}_{5}$} & $\mathrm{CrTiF}_{5}$ & 26 & 78 & 1.78 \\
\hline & $\mathrm{CrVF}_{5}$ & 40 & 51 & 0.86 \\
\hline \multirow[t]{2}{*}{$\mathrm{Hex} . \mathrm{Cs}_{2} \mathrm{NaCrF}_{6}$} & $\mathrm{Cs}_{2} \mathrm{MnCoF}_{6}$ & 53 & 61 & 1.99 \\
\hline & $\mathrm{Cs}_{2} \mathrm{MnNiF}_{6}$ & 61 & 78 & 2.40 \\
\hline
\end{tabular}

zations of the sublattices thus formed are in opposition (Fig. 10). In the fluorides only the octahedral sites are occupied by the transition element cations and both magnetic sublattices 
are therefore composed of octahedra. Ferrimagnetism results then from the way in which the octahedra are joined. In the fluorides of the $\mathrm{BaTiO}_{3}$ type (hexagonal), for example, one of the sublattices consists of octahedra linked by corners and in the other sublattice the octahedra are linked by faces. For the chiolites the octahedra of one of the sublattices are linked by the two corners while in the second they are linked by four corners. In the ferrimagnetic fluorides of the type $\mathrm{MnAlF}_{5}$ the octahedra are linked via edges for one of the sublattices and via corners for the other.

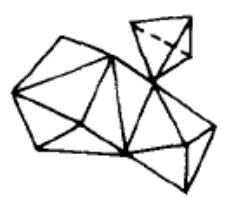

Garnet

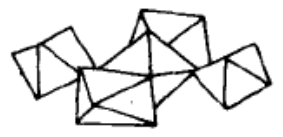

Chiolite

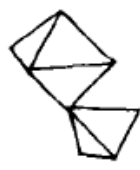

Spinel
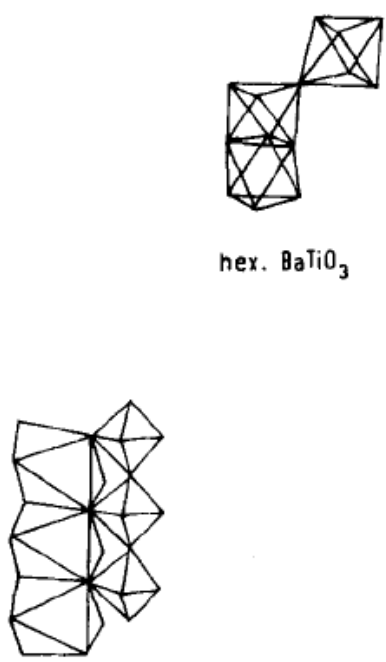

hex. $\mathrm{BaTiO}_{3}$

\section{A127.10}

$$
\operatorname{Mn~AlF} F_{5}
$$

Fig. 10. Arrangement of polyhedra in ferrimagnetic oxides and nuorides

Very few ferromagnetic fluorides are presently known $\left(\mathrm{K}_{2} \mathrm{CuF}_{4}, \mathrm{TbF}_{3}, \mathrm{LiTbF}_{4}\right)$, but further examples will probably be discovered in due course.

\subsection{Optical Properties}

The optical properties of saltlike fluorides are typically those of insulators and therefore are not, in principle, different from those of other halide or oxide insulators. The interesting characteristics of the $\mathrm{F}^{-}$ion give rise, however, to some unique properties which will be discussed below.

When an insulating crystal, free of defects, is exposed to a beam of photons of increasing energy, one first observes absorption bands corresponding to vibrational transitions. With increasing incident energy of the photons, the absorption bands corresponding to the electronic transition between cation orbitals appear (d-d, f-f, d-f, s-p, ...). The next absorptions to appear are charge transfer bands arising from electron transfer from the anion to the cation (Fig. 11). We will now examine these different regions of the optical spectrum.

\begin{tabular}{|c|c|c|c|c|c|}
\hline $10^{4}$ & & 3.2 & 1,5 & & $1^{10^{-3}}$ \\
\hline$E[e V]$ & & & & & \\
\hline$x$-ray & UV & VIS & & $\mid R$ & $\begin{array}{l}\text { Havio } \\
\text { irequencie }\end{array}$ \\
\hline & $\begin{array}{l}\text { charge } \\
\text { transter }\end{array}$ & $\begin{array}{c}d-d, f-t, d-f \\
\text { transitions }\end{array}$ & & $\begin{array}{l}\text { Lattice } \\
\text { ibrations }\end{array}$ & \\
\hline $8 \cdot 10^{7}$ & & 25000 & 12000 & & 10 \\
\hline$\tilde{v}\left[\mathrm{~cm}^{-1}\right]$ & & & & & $A 127,11$ \\
\hline
\end{tabular}

Fig. 11. Interaction between light and crystal as a function of photon energy.

As previously shown in Section 4.1, fluorides are insulators with a large band gap. As a result, the compounds of the elements not absorbing in the visible range (i.e. the lighter elements and those for which the $d$ and $f$ layers are full or empty) will be transparent up to the UV region. Magnesium fluoride, for example, as a perfect crystal, will be transparent from $10^{6} \mathrm{~cm}^{-1}$ (corresponding to the energy threshold where transitions from the valence to the conduction bands occur) to $10^{3} \mathrm{~cm}^{-1}$ (maximum frequency of lattice vibrations).

The transparency of fluorides has led to their use as windows or prisms in optical instruments. Another well known application is the use of thin layers of magnesium fluoride for coating lenses to decrease reflections and increase the luminosity. These thin layers of magnesium fluoride are also condensed onto solar panels for space satellites.

This property renders fluorides particularly attractive as host lattices for the luminescent ions. In fact, the luminous energy produced by these ions will sustain a very weak decrease by parasitic absorption in fluorinated materials.

At the other end of the spectral range of interest, i.e. the infrared, the fluorides do not behave differently from other compounds, in particular, the oxides. The excitation frequencies depend primarily on the mass of the vibrating atoms. They are generally located below $1000 \mathrm{~cm}^{-1}$ for fluorides as well as oxides.

Let us now examine the electronic spectrum of the $d$ and $f$ transition elements which are located in the visible and ultraviolet range $\mathrm{e}^{\mid 33.34\}}$.

For the delements, for which the electronic levels responsible for those transitions correspond to the external orbitals which are subjected to the ligand field, two types of absorption are observed. The most intense absorptions come from charge transfers, transfer of the p electron of the ligand to the d orbitals of the central ion; they are allowed by Laporte's rule. The weakest correspond to internal transitions in the $\mathrm{d}$ configuration and are therefore forbidden by this same rule.

In the fluorides, the transfer of an electron from the $\mathrm{F}^{-}$ ligand to the central atom requires a large amount of energy due to the electronegativity of the halogen. As a result, the corresponding absorptions appear in the ultraviolet range and are not visible. This explains the relative transparency of fluorides as compared with oxides or chlorides: the crystals of $\mathrm{FeF}_{3}$ are slightly green in hue while those of $\mathrm{FeCl}_{3}$ are deep violet and those of $\mathrm{Fe}_{2} \mathrm{O}_{3}$ are brown and almost completely opaque. This property renders the fluorides particularly attractive for magnetooptic research and applications.

The spectroscopic properties of compounds containing lanthanoids are of great practical value. The important applica- 
tions to which these materials lead are well known, such as the laser operating with a YAG crystal $\left(\mathrm{Y}_{3} \mathrm{Al}_{5} \mathrm{O}_{12}\right)$ doped with neodymium or television screens using the fluorescence of the yttrium oxide sulfide doped with rare earths.

The spectroscopic properties of 4 f elements are notably different from those of the $\mathrm{d}$ elements: The principal difference derives from the fact that the 4 f electrons are protected from the crystalline field by external shells. The energy levels are therefore discreet and result in narrow spectral lines. Another difference is the ability of the lanthanoids to afford fluorescent spectra while this phenomenon is only rarely observed for the $\mathrm{d}$ elements. This behavior can be understood when one looks at the configuration curves in Figure 12. The curves of lower energy correspond to the ground level, and those of higher energy to the excited states. The distance $r$ represents the distance from the cation to the anion which is not exactly the same for the two states. In the case of lanthanoids the minimum of the excited state is found inside the ground state curve. Since these minima in the configuration curves are almost superimposed, an excitation can be followed by an emission (Fig. 12a). In contrast, for the d elements which are less well protected from the crystal fields $\Delta r$ varies considerably and the minimum of the configuration curve of the excited state is found outside of that of the ground state. The system then returns to the ground state without emission, with energy being dissipated by nonradiative emission (Fig. $12 \mathrm{~b})^{[35]}$.

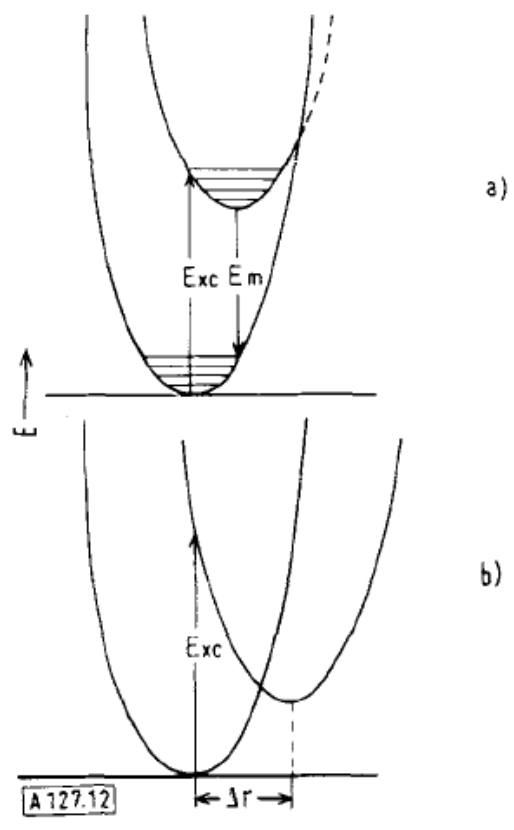

Fig. 12. Diagram of configuration curves for a) a luminescent center and b) a non-luminescent center.

Although the $4 \mathrm{f}$ orbitals mix only slightly with the anion orbitals, a certain covalence effect nevertheless exists. This leads to a broadening and to a red shift of the f levels. In the fluorides the covalence will clearly be the weakest, and their absorption and fluorescent spectra are therefore characterized by narrow bands identical with those of isolated ions.

A word should be said about the lifetime of the excited levels. Like the d-d transitions, the f-f transitions are theoretically forbidden by Laporte's rule. They are observed, however, because the wave functions of the electrons taking place in these transitions do not have a pure $f$ character but also a certain amount of $p$ character due to covalency. It is in the fluorides that the $f$ character will be most marked owing to the ionic nature of the bond. Several results derive from this. The more a transition is forbidden, the weaker will be the corresponding emission. In addition, the life of the excited state will be greater as the forbidden state becomes narrower, for a system will return all the more quickly to its ground state if the transition which accompanies this change is possible. It can be then concluded that fluorides have some weak spectral lines and that the duration of the excited states will be long.

The luminescence phenomenon in the rare earth compounds often results from energy transfer. The ion responsible for luminescence, which is named the activator, cannot receive energy directly but only through another ion called the sensitizer (Fig. 13). The sensitizer can be another cation $\left[(\mathrm{Ce}, \mathrm{Tb}) \mathrm{F}_{3}\right.$, $\left.\mathrm{S}=\mathrm{Ce}^{3+}, \mathrm{A}=\mathrm{Tb}^{3+}\right]$ or an anion $\left[(\mathrm{Y}, \mathrm{Eu}) \mathrm{VO}_{4}, \mathrm{~S}=\mathrm{VO}_{4}^{3-}\right.$, $\left.\mathrm{A}=\mathrm{Eu}^{3+}\right]^{[35]}$. The energy transfer requires a mixing of the

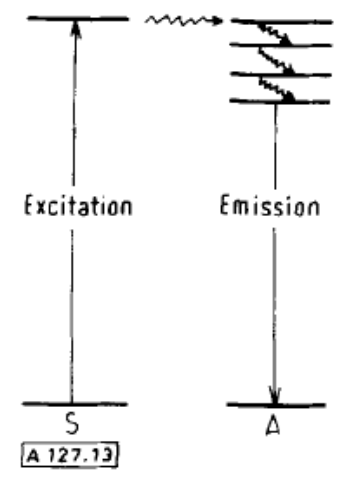

Fig. 13. Energy transfer from a sensitizer (S) to an activator (A)

wave functions of $\mathrm{S}$ and of $\mathrm{A}$. In the fluorides, the activator cation is separated from the sensitizer ion by the $\mathrm{F}^{-}$. The single charge of the fluoride ions leads to high coordination numbers ( 9 in $\mathrm{YF}_{3}, 11$ in $\left.\mathrm{LaF}_{3}\right)$ and the transfer phenomena are possible only by superexchange. Now as we have seen, the overlap of the f orbitals of lanthanoids and the $p$ orbitals of fluorine are weak and the energy transfer difficult. As a result, the fluorides are generally less efficient luminophores than oxides.

This conclusion should, however, be qualified. In the case of the divalent lanthanoids, the energy difference which separates the $4 f^{n}$ and $4 f^{n-1} 5 d^{1}$ configurations are much smaller than in the case of trivalent rare earths. To the transitions which involve the $5 \mathrm{~d}$ levels, there correspond large and intense absorption bands as in the case of the $3 \mathrm{~d}$ elements. In addition, some nonradiative transitions can occur from this band to a $4 \mathrm{f}$ excited level which in turn allows an intense fluorescence (Fig. 14).

It is understood that in order to obtain high emission yields it is desirable to have as high a concentration of the activator as possible. However, if this concentration goes beyond a certain value the yield diminishes rapidly. If the probability of transfer from one activator cation to another becomes large as a result of the concentration, the energy of excitation is dissipated in the lattice in the form of heat and no longer contributes to luminescence. In the fluorides 
these transfers are difficult due to the blocking effect of fluorine and the critical concentration will be much higher than for the oxides.

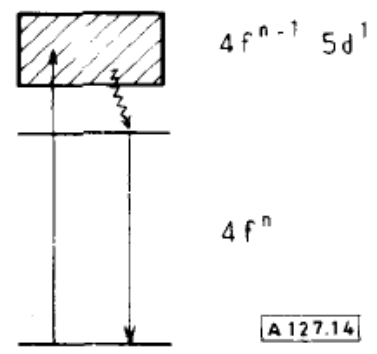

Fig. 14. Energy transfer within a divalent lanthanoid ion

The transparency of the fluorides in the ultraviolet range, as was previously noted, will likewise play a double role. Excitation generally occurs in this wave length range. If the luminescence directly involves the activator, this property will be advantageous because no excitation energy will be dissipated in the lattice. In contrast, the $\mathrm{F}^{-}$ions will be poor sensitizers compared with such ions as $\mathrm{VO}_{4}^{3-}, \mathrm{BO}_{3}^{3-}$, and $\mathrm{PO}_{4}^{3-}$ which readily effect transfers.

This set of specific properties helps in defining the areas of applications of rare earth fluorides. Generally, fluorides are not such good luminophores as oxides for the reasons mentioned above. On the other hand, however, their use has been proposed in the area of lasers for example, as binary or ternary fluorides of yttrium doped with neodymium. The reasons behind this choice are good transparency in the ultraviolet range, which leads to favorable behavior on excitation, slight attenuation, and a sharpness of the emission ray. Nevertheless, these devices do not appear to offer any great advantage over the oxides.

In the field of infrared to visible conversion, fluorides have proved to be exceptionally well suited, and are supplanting the other materials ${ }^{[36]}$. Efficient up-conversion is observed in the compounds containing two rare earth ions such as $\mathrm{Yb}^{3+}$ and $\mathrm{Er}^{3+}$ (Fig. 15). The levels of these ions are such that $A_{2}-A_{1} \approx B_{2}-B_{1} \approx B_{3}-B_{2}$. The following process takes place: the $\mathrm{Yb}^{3+}$ ion absorbs an energy photon $h v_{1}$ in the infrared range and is excited from the $A_{1}$ level to the $A_{2}$ level. Excitation transfer then occurs between neighboring $\mathrm{Yb}^{3+}$ and $\mathrm{Er}^{3+}$ ions; the $\mathrm{Yb}^{3+}$ ion falls back to the $\mathrm{A}_{1}$ level and the $\mathrm{Er}^{3+}$ ion is promoted from the $\mathrm{B}_{1}$ level to the $B_{2}$ level. If the excited state $B_{2}$ has a sufficient lifetime, which is the case with the fluorides, a second photon $h v_{1}$, can be absorbed by $\mathrm{Yb}^{3+}$ (transition $\mathrm{A}_{1} \rightarrow \mathrm{A}_{2}$ ) before the $\mathrm{Er}^{3+}$ ion returns to the ground state. A second excitation transfer is then possible, the $\mathrm{Er}^{3+}$ ion moving into the $\mathrm{B}_{3}$ state while

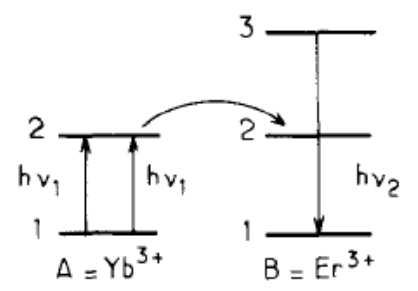

A 127.15

Fig. 15. Conversion of infrared into visible light. the $\mathrm{Yb}^{3+}$ ion falls back to the $\mathrm{A}_{1}$ level. The final return of the $\mathrm{Er}^{3+}$ ion from $\mathrm{B}_{3}$ to $\mathrm{B}_{1}$ leads to the emission of a photon $h v_{2}$ such that $v_{2} \approx 2 v_{1}$. The frequency $2 v_{1}$ is located in the visible range.

This process can be generalized as the successive energy addition of three, or even four identical photons, or also as the energy addition of two photons of different energies. In this latter case, the fluorescence photon $h v_{3}$ obeys approximately the relationship $v_{3} \approx v_{2}+v_{1}$, where $v_{1}$ and $v_{2}$ are the frequencies of the two incident photons.

This phenomenon aroused considerable interest when it was shown that the yield is considerably improved by using $\mathrm{Yb}^{3+}$ as the sensitizer ion. It is often called the "Auzel effect" after its discoverer ${ }^{[36]}$.

This mechanism effects the transformation of an infrared radiation into green light by addition of two photons, or into blue light by addition of three photons. Several applications have been envisioned. The Auzel effect can be utilized in quantum meters for detection and visualization of infrared radiation. Electroluminescent diodes are also feasible: a fluoride doped with ytterbium and erbium or with thulium is deposited in powder or single crystal form on the surface of a gallium arsenide diode emitting in the infrared. The radiation is transformed by the fluoride into visible blue or green light. Fluorinated matrices which lead to better yields are alkali-yttrium fluorides.

Yet another phenomenon capable of application has recently been discovered ${ }^{[3]}$. It involves not only the $\mathrm{f}-\mathrm{f}$ transitions which were previously noted, but also $\mathrm{f}-\mathrm{d}$ transitions. While the transfer of an electron into the $5 \mathrm{~d}$ orbital needs $90000 \mathrm{~cm}^{-1}$ in the case of the free $\mathrm{Gd}^{3+}$ ion, such a transfer in the case

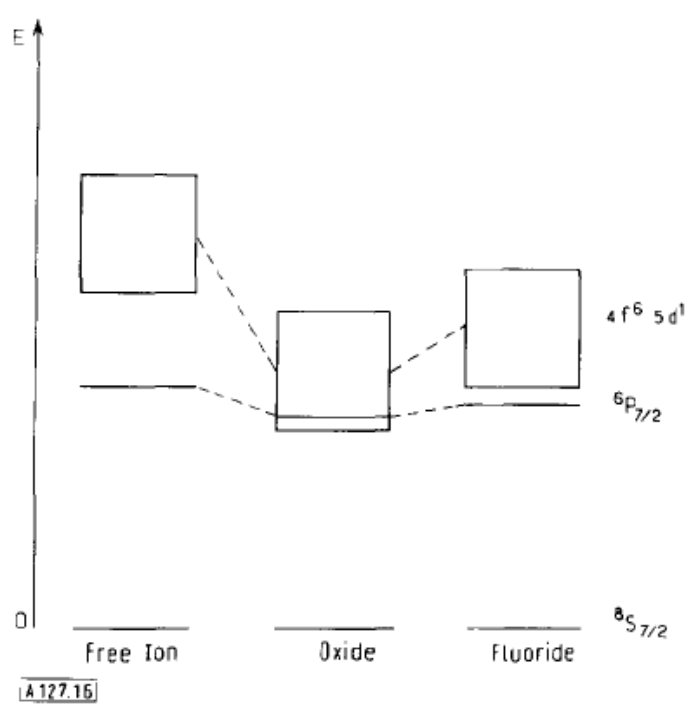

Fig. 16. Energy of the ${ }^{6} \mathrm{P}_{7 / 2}$ level in relation to the $4 \Gamma^{6} 5 \mathrm{~d}^{1}$ band in $\mathrm{Eu}^{2+}$

of divalent europium only requires $40000 \mathrm{~cm}^{-1}$. Divalent europium contains seven $f$ electrons, which corresponds to a high correlation energy as is the case for all half-occupied orbitals. As a result, a large energy difference separates the ground state ${ }^{8} \mathrm{~S}_{7 / 2}$ of europium from the first excited level ${ }^{6} \mathrm{P}_{7 / 2}$ of the $4 f^{7}$ configuration. This system can, therefore, lead to emission of ultraviolet radiation for which practical applications exist. However, this type of transition is not generally observ- 
able, since the $5 \mathrm{~d}^{1}$ levels are located above the ${ }^{6} \mathrm{P}_{7 / 2}$ level only in the free ion. In most compounds of europium, and especially in the oxides, these levels form a band and overlap with the excited states of the $4 f^{7}$ configuration (Fig. 16). This band, corresponding to the $5 \mathrm{~d}$ external orbitals, is very sensitive to the crystal field. Only in certain fluorides does it have a sufficiently high energy for the transition ${ }^{6} \mathrm{P}_{7 / 2}{ }^{8} \mathrm{~S}_{7 / 2}$ to appear. The emitted light is highly monochromatic and can be used either for developing lasers in the near UV or for xerography.

\section{Conclusion}

After his successful research on fluorine, Moissan queried: "Will fluorine never have any applications? It is very difficult to answer this question". History has answered in the affirmative: fluorine has become an industrially important element. In the field of materials, the applications of mineral fluorides are still relatively few and account for only small amounts. In pure research, however, these compounds attract considerable interest owing to their unusual and specific properties. No doubt this speculative work will lead to important applications in the future, some of which can already be discerned. But is that all that really matters? Moissan finished his commentary on the use of fluorine with this phrase: "In addition, I can say in all sincerity I was hardly thinking about it at the moment when I undertook this work, and I believe that all the chemists who have attempted such research before me were not thinking further of it: Scientific work is the search for truth".

[1] L. Domange in P. Pascal: Nouveau Traité de Chimie Minérale, Masson, Paris 1960

[2] P. Hagemmuller: Les Propergols. Gauthiers-Villars, Paris 1966.

[3] W. H. Zachariasen, Acta Crystallogr. 4. 231 (1951).

[4] B. Tanguy, M. Pe:at, J. Portier, and P. Hagenmuller, Mater. Res. Bull. 6. $57(1971)$.
[5] M. Bayard, M. Pouchard, P. Itactesisturit, and A. Wold, J. Solid State Chem. 12. 41 (1975).

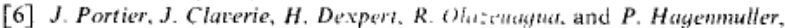
C. R. Acad. Sci. Paris 270, 2142 (1970)

[7] J. Portier. B. Tangu:. A. Morell, R. Pauthenet, R. Olazcuagua, and P. Hagenmuller, C. R. Acad. Sci. Paris 270, 821 (1970).

[8] A. Marbeuf, G. Demazeau, S. Turell, P. Hagenmuller, J. Derouet, and P. Caro, J. Solid State Chem, 3, 637 (1971).

[9] B. Tangui, M. Pezat, C. Fontenit, and C. Fouassier, C. R. Acad. Sci. Paris 277. $25(1973)$

[10] C. Dragon and F. Theret, C. R. Acad. Sci. Paris 268, 1867 (1969).

[11] R. Juza, R. Sieters, and W. Jumy, Naturwissenschaften 53, 551 (1966).

[12] D. Bubel, Struct. Bonding (Berlin) 3, 1 (1967).

[13] A. Trexsatud and J. Portier: Applications des mesures magnétiques aux problèmes structuraux des fluorures des elements de transition in appareillages et techniques de caractérisation des composés minéraux solides. Masson, Paris 1971.

[14] J. Gramec, J. Portier, M. Pouchard, and P. Hagemmuller, J. Inorg. Nucl. Chem.. in press.

[15] E. Alier and R. Hoppe, Z. Anorg. Allg. Chem, 405, 167 (1974).

[16] G. Demazea, M. Pouchard, and P. Hagenmuller, J. Solid State Chem. 9,202 (1974).

[17] W. Klenum, Bull. Soc. Chim. Fr. 1956, 1325.

[18] K. Leary and N. Bartlett, J. Chem. Soc. Chem. Commun. 1972, 903.

[19] B. Tanguy, M. Vasse, and J. Portier, Rev. Chim. Miner. 10, 63 (1973).

[20] $R$ de Pape, C. R. Acad. Sci. Paris 260, 4527 (1965).

[21] $R$. Collongues: La non-stoechiométrie. Masson, Paris 1971.

[22] P. Faugeras, lactualité Chim. 2, 14 (1975).

[23] J. Schröder, $5^{\text {th }}$ Eur. Symp. Fluorine Chem., Aviemore 1974, Abstr. M. 3.

[24] J. Claverie, G. Campet. M. Perigord, J. Portier, and J. Rate: Mater. Res. Bull. 9, 585 (1974).

[25] Matsushita Electric Industrial Co., Jpn.-Pat. H0I m 43/00.

[26] B. C. la Roy, A. C. Lilly, and C. O. Tiller. I. Electrochem. Soc. 120. 1668 (1973)

[27] N. N. Greenwood, A. T. Howe, and F. Menil, J. Chem. Soc. Al971, 2218.

[28] O. Berkooz, M. Malamud, and S. Shtrikman, Solid State Commun. 6,185 (1968).

[29] J. Ratez and M. Dahadie. Rev. Chim. Miner. 12, 765 (1975).

[30] J. Racez, G. Campet, J. Claterie, H. Baudry, J. Grannec, J. Portier. and M. Perigord, Patent Anvar n" 73.373 (1973)

[31] J. B. Goodenough: Magnetism and Chemical Bond. Wiley-Interscience, New York 1963.

[32] A. Tressaud, Adv. Inorg. Chem. Radiochem. 19 (1976). in press.

[33] B. N. Figgis: Introduction to Ligand Fields. Wiley-Interscience, New York 1966.

[34] G. H. Dieke: Spectra and Energy Levels of Rare Earth lons in Crystals. Wiley-Interscience. New York 1968.

[35] G. Blasse and A. Bril, Philips Tech. Rev. 31, 10, 304 (1970).

[36] F. Auzel, C. R. Acad. Sci. Paris 262, 1016 (1966).

[37] B. Tanguy, P. Merle, M. Pezat, and C. Fotassier. Mater. Res. Bull. 9. 831 (1974). 